\title{
Threats to the monkeys of The Gambia
}

\author{
E.D. Starin
}

There are five, perhaps only four, monkey species in The Gambia and all are under threat. The main problems are habitat destruction, hunting of crop raiders and illegal capture for medical research. The information presented here was collected during a long-term study from March 1978 to September 1983 on the socio-ecology of the red colobus monkey in the Abuko Nature Reserve. Further information was collected during brief periods between February 1985 and April 1989 on the presence of monkeys in the forest parks. It is not systematic nor extensive, but it indicates clearly that action is needed if monkeys are to remain as part of the country's wildlife. The most pressing need is for survey work to supply the information needed to work out a conservation plan.

\section{The Gambia - an overview}

The Gambia forms a narrow band on either side of the river Gambia for some $475 \mathrm{~km}$. The country varies in width from about 24 to $48 \mathrm{~km}$ and is bordered on three sides by the Republic of Senegal.

The Gambian climate consists of a long dry season with a shorter, but intense, rainy season. During the dry season, the days are hot, the nights and early mornings are cold and the harmattan, a hot, dry, north-easterly wind, blows from the Sahara and dries up the countryside, causing much haze, dust and low humidity. The rains, moving in from the east, generally start in mid-June and end by October. During this time, a damp south-west monsoon wind often uproots shallow-rooted trees (particularly some Ficus species and oil palms) and blows the roofs off local huts. The long-term effects of the Sahelian drought are recognized as the country's most salient climatic feature.

The country has a total land area of $10,350 \mathrm{sq} \mathrm{km}$ and a total human population of 750,000 (UNDP, 1987), resulting in an average density of 72.5 people per sq $\mathrm{km}$. This makes The Gambia one of the most densely populated countries in Africa. The mean annual population growth is 208 estimated at 3.3 per cent, which means that the population doubles every 20 years. Only about 20 per cent of the population is urban, the rest living scattered through the country in small villages. As a result there is virtually no undisturbed forest and very few protected areas. The remaining forest cover ( 3.4 per cent of the country) is rapidly being converted into tree and shrub savannah through a combination of increasing human population, annual bushfires, uncontrolled exploitation, uncontrolled grazing by livestock (the 1987/1988 National Agricultural Sampling Survey indicated total populations of 282,000 cattle, 175,000 sheep and 208,000 goats), and increasing periods of drought. There are few areas that have not been modified by fire or cultivation and that do not constitute secondary vegetation; the mangrove swamps are among the least changed, although many stands are cut for fuel (Rains and Johnson, 1976). Overall, The Gambia is a country of open tree and shrub savannah with islands of relict forests in the moister western part, similar to those of other countries in the Sudan-Guinea zone (Ellenberg et al., 1988).

\section{Threats to the monkeys}

There are five monkey species in The Gambia: Oryx Vol 23 No 4, October 1989 
red colobus Procolobus badius temminckii; green monkey Cercopithecus aethiops sabaeus; patas monkey Erythrocebus patas; Guinea baboon Papio papio; and Campbell's monkey Cercopithecus campbelli. They face a number of threats, the main ones being habitat destruction, hunting of crop raiders and smuggling of monkeys into Senegal for export to foreign biomedical laboratories.

\section{Habitat destruction}

Habitat destruction is one of the most serious threats to primates worldwide and The Gambia is no exception. The isolation of, and then gradual degradation of forested areas, is in fact the real problem in The Gambia. The fragmentation of the remnant areas compounds the threat by isolating small populations, which are then vulnerable to local extinctions. Between 1982 and 1985 a 'mixed forest' of approximately 40 ha was reduced to savannah in the coastal area of the Western Division and two troops totalling over 35 red colobus completely disappeared. It is assumed that they died in bush fires and/or were shot. In fact, red colobus appear particularly vulnerable to bush fires. A fire that swept through Fathala Forest in Senegal in 1980 killed at least six adult red colobus, and another fire in the Lower River Division in The Gambia killed at least five red colobus in March 1989.

\section{Hunting}

Hunting statistics are hard to obtain. I found very little evidence of hunting of monkeys for food and no evidence of hunting for medicinal purposes, bait or skins. I received two reports from the coastal area that people were hunting monkeys (with guns and/or dogs and clubs) for food and that red colobus were preferred because they were 'bigger and easier to catch'. There was, however, evidence of hunting baboons, patas monkeys and green monkeys on quite a large scale because of their crop raiding activities.

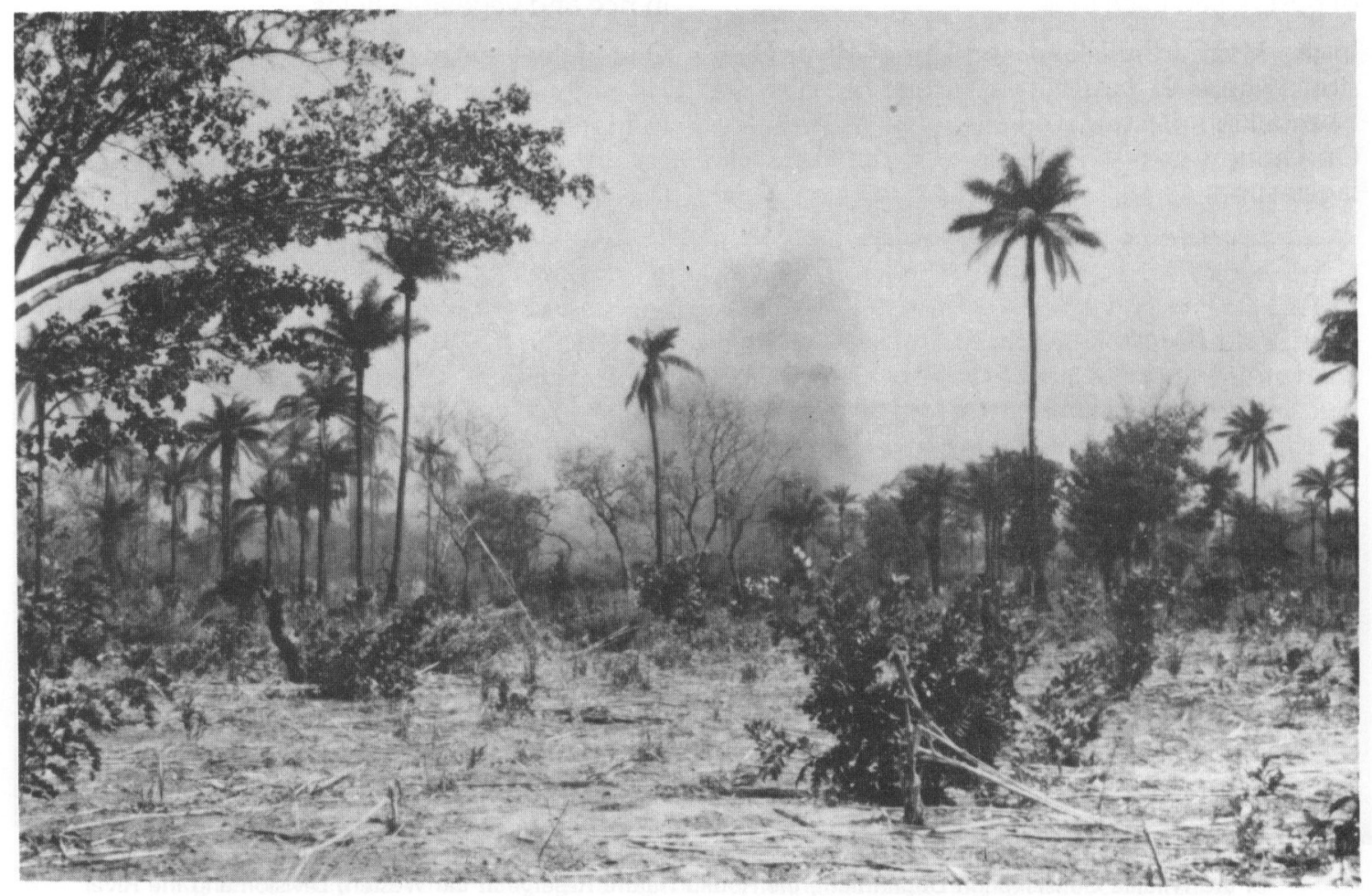

The bushfires that rage through The Gambia are responsible for much habitat destruction (E.D. Starin). 


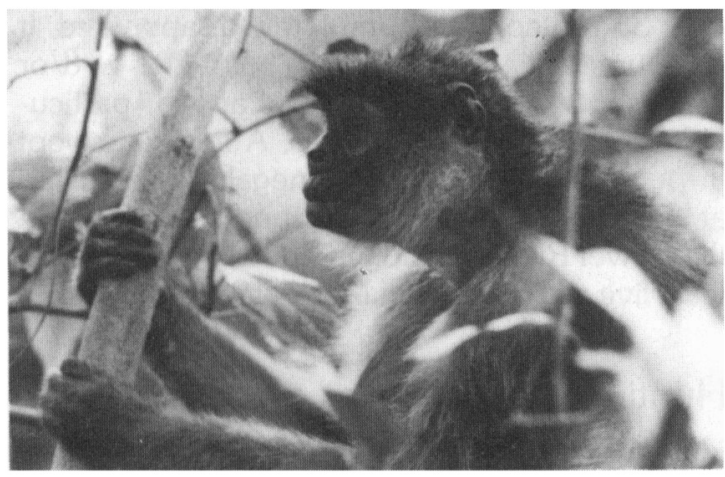

Female red colobus monkey (E.D. Starin).

No records are available on the exact amount of damage done to crops by wildlife in The Gambia. Parker (1973) stated that there was general agreement that the major mammalian pest was the warthog, followed by baboons, green monkeys, patas monkeys and hippos, and that measures taken included the posting of guards, organizing communal drives and shoots and the assistance of the Police Field Force in wiping out the pests. There are no data available on the exact number of pests killed each year.

In the MacCarthy Island and Upper River Division (Figure 1) large scale village hunts have been taking place for at least the past 10 years. One hunt was described to me in detail: 11 villages supplied sticks, cutlasses and guns while another supplied all the cartridges for a monkey kill, which claimed approximately 300 victims (the monkey victims were not specified as to species). The hunts appear to be identical to the monkey drives carried out on a much larger scale in Sierra Leone up until the mid-1960s (Jones, 1950; Tappen, 1964) and throughout The Gambia in the 1940s and 1950s (H. Oliver, pers. comm.; G. H. Smith, pers. comm.).

Hunting of monkeys as agricultural pests is probably exerting serious pressure on baboons, patas monkey and green monkey populations in The Gambia-particularly in the MacCarthy Island and Upper River Division where the communal monkey hunts are annual-and often biannual-affairs.

In questionnaires put to farmers by the Mixed Farming Unit of the United States Agency for International Development in 1982, over 69 per cent of the respondents said that monkeys, baboons, warthogs and rodents were a major problem in groundnut, sorghum and millet fields, while over 61 per cent said they were major pests in rice and vegetable fields.

One of the local methods of crop protection is to kill a monkey and then hang the carcass in a field to frighten other monkeys away. I saw three red colobus and two green monkey 'scarecrows' in the Western Division and one red colobus

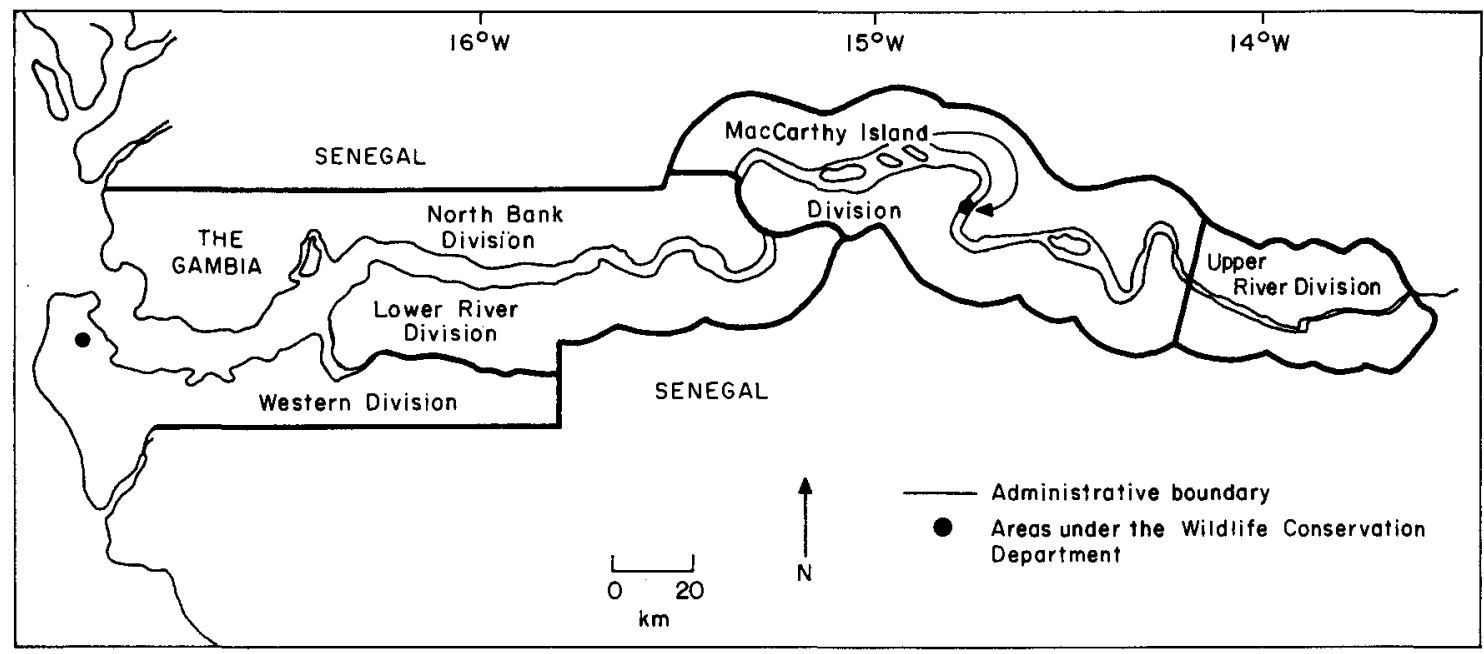

Figure 1. Map of The Gambia showing its five administrative divisions and the two areas under the protection of the Wildlife Conservation Department, the Abuko Nature Reserve in the Western Division and the River Gambia National Park in the MacCarthy Island Division. 
'scarecrow' in the Lower River Division. These 'scarecrows' were also common in Senegal. I was not able to get any information on how effective the farmers thought this form of protection was. Possibly related to this practice was the observation on three separate occasions of dead red colobus hanging in trees at the edge of forests. When I questioned local people about these dead colobus I was told that they were there to keep the 'devils' away.

Red colobus are not considered major crop raiders and they are not victims of the major monkey drives-probably because they do not inhabit many of the areas where the drives take place. At present, they are killed only infrequently compared with the baboons, greens and patas monkeys. Ironically, one female was killed just outside the Abuko Nature Reserve for eating mango flowers on one of the village trees, while another five were killed by young boys with dogs for 'sport' outside one of the forest parks in the Western Division. In March 1989 I was told by three separate farmers in the Western Division that red colobus were now coming in and raiding corn and watermelon fields and they were beginning to shoot them.

Campbell's monkeys are not included in any of the observations because they have been virtually wiped out. During the entire time I spent in The Gambia I knew of only one Campbell's monkey - a lone subadult male who spent about 6 months in the Abuko Nature Reserve and then disappeared. As I travelled through The Gambia I found that most people had seen Campbell's monkeys in the past (not specified how long ago) and considered them the worst crop raiders of all'. In three different villages in the Western Division I spoke to farmers who told me that they had killed them whenever they saw them because they were 'major pests'. They are still living in the Casamance region of Senegal in observable numbers; I also encountered a group of six men there who had eaten monkey and claimed that their favourite was Campbell's monkey.

Monkey pets are probably byproducts of hunting; there is only a very small-scale trade in live

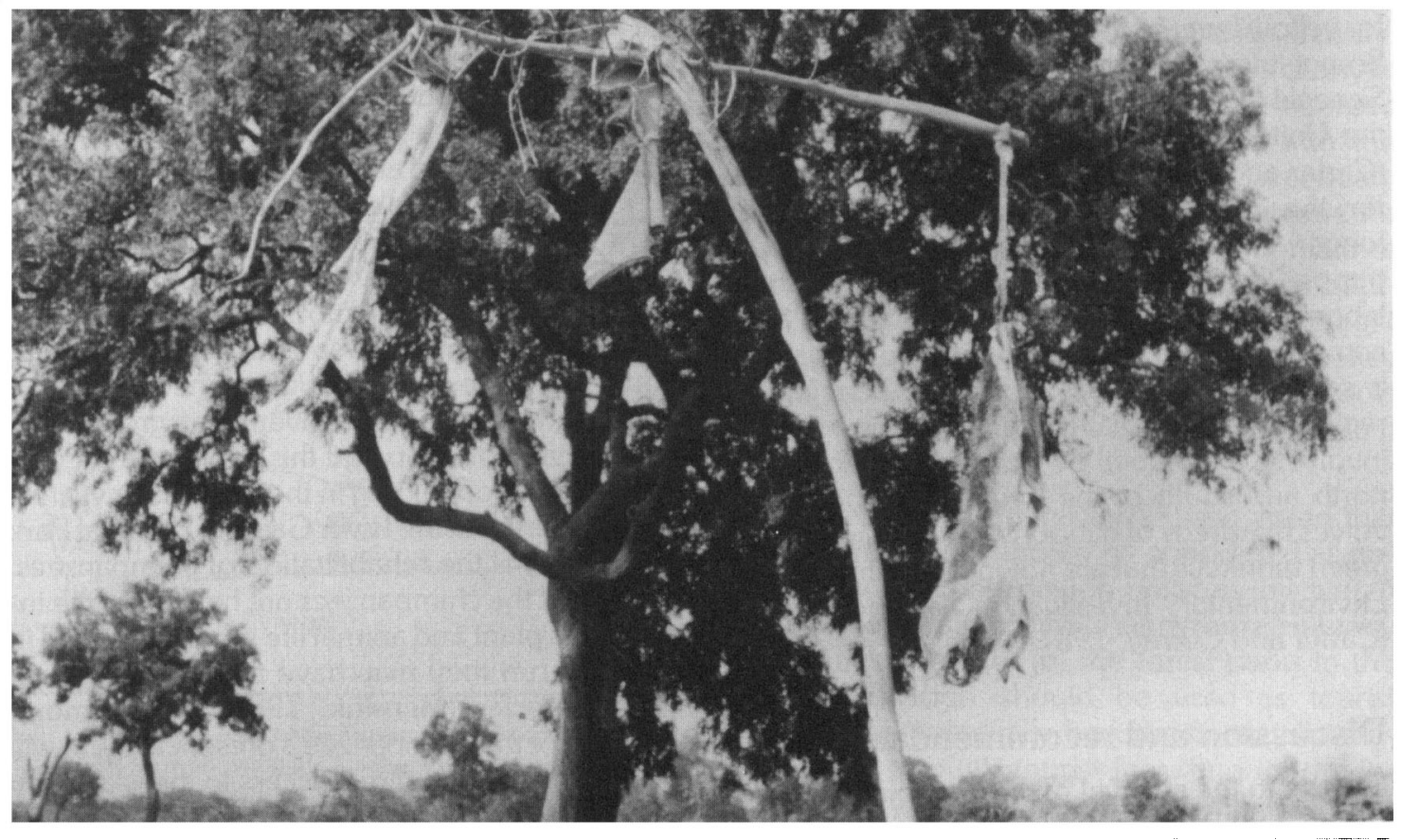

A green monkey 'scarecrow' hanging in an agricultural field is intended to frighten away crop-raiding monkeys (E.D. Starin). 
monkeys. Between 1978 and 1983 I heard of only 12 monkeys (four baboons, three green monkeys, three patas monkeys and two red colobus) being offered for sale in the Western Division and three baboons in the MacCarthy Island Division. During the same period I knew of another 10 (four patas, three green monkeys and three baboons) being kept as pets on short chains in the Western Division.

Baboons, patas monkeys and green monkeys and now maybe red colobus, are probably being forced into crop raiding because of the degradation of natural areas, the increase in agricultural lands and the expanding human population. The increase in monkey-man conflicts is likely to hamper conservation efforts by creating negative feelings towards all primates in general, as pointed out by Mittermeier (1987).

\section{Capture for medical research}

Capture for medical research probably removes a number of primates from The Gambia each year. The only instance of internal medical research was in January 1979 when 12 red colobus and seven green monkeys were shot and tested for yellow fever antibodies (Monath et al., 1980). Smuggling primates, particularly baboons, into Senegal for export to laboratories in France and the United Kingdom is probably quite frequent (Carter and Currey, 1987). Although it is illegal, for the past few years (and probably much longer) a minimum of 200 monkeys have been trapped, smuggled into Senegal and exported to laboratories. According to D. Currey (pers. comm.) the trapping/smuggling/export network is so well co-ordinated within the Senegambia region that it must have been going on for years, involving a number of Gambian villages both north and south of the river, and probably involves hundreds of baboons, patas monkeys and green monkeys that are not included in the 1987 Environmental Investigation Agency report (Carter and Currey, 1987).

\section{Discussion and recommendations}

Threats to the survival of the Gambian monkeys come from three sources: habitat destruction, hunting of crop raiders and smuggling of illegally trapped monkeys into Senegal for export pur212 poses. Baboons, green monkeys and patas monkeys are affected by all three, while the red colobus, at present, are basically victims of habitat destruction. It appears that the Campbell's monkeys have been virtually eliminated from The Gambia.

The conservation of Gambian monkeys cannot be considered in isolation from the conservation of the habitat and the economic and social interests of the people. The small size of The Gambia, the intensity of cultivation (two-thirds of the population is engaged in agriculture according to UNDP, 1987), and increase of the human population and its livestock probably preclude the possibility of establishing any large parks or reserves.

Two departments deal with conservationoriented issues: the Wildlife Conservation Department and the Forestry Department. The Wildlife Conservation Department is responsible for two legally protected areas, the 107-ha Abuko Nature Reserve in the Western Division and the River Gambia National Park, a group of islands totalling 579 ha in the MacCarthy Island Division. In both areas it is illegal to graze, hunt, fell trees or light fires. In neither area, however, is the protection of indigenous primates or habitats a priority. In the Abuko Nature Reserve the natural water course has been altered, exotic plants and animals introduced and parts of the gallery forest were cleared to make way for a zoo housing mostly exotic animals. Furthermore, selected patches of savannah were burned and used as sites to provision green monkeys and patas monkeys with groundnuts so that these monkeys could be more easily photographed. This was particularly unfortunate given that groundnuts are a local food crop and this may have encouraged more crop raiding in the immediate vicinity of the reserve. In the River Gambia National Park the priority is the rehabilitation of chimpanzees. The effect the chimpanzees are having on the indigenous plant and animal life is unknown and in the long run they may have adverse effects on native species (Mensink, 1986). Furthermore, because of the chimpanzee's presence, there will probably never be direct access to the islands by the public for educational or touristic purposes.

The Forestry Department protects 66 parks totalling about 34,027 ha. Within the forest parks

Oryx Vol 23 No 4, October 1989 
grazing, hunting, felling trees or lighting fires is illegal. Unfortunately, there are insufficient funds for patrol programmes and fires have been started. In fact, one fire resulted in a 25 per cent drop in volume in standing timber in one forest. The protection of the indigenous primates and habitats is not a priority for the Forestry Department. There is, however, an essential compatibility of forestry objectives and primate conservation. For example, afforestation is taking place within the forest parks with native species and two of the forest parks (the 64-ha Pirang forest and the 50 -ha Bijilo forest in the Western Division) under the protection of the Forestry Department are being kept as relict forest patches with no felling, grazing, hunting or fires allowed and no selective cutting or planting of timber trees. In short, these are the only two parks in The Gambia where the original vegetation and inhabitants are being left alone and no exotic trees or animals are being introduced. Furthermore, Pirang is one of the most thoroughly investigated parks in The Gambia (Ellenberg et al., 1988). Some of the forest parks, particularly in the Western Division and North Bank Division (i.e. Katilenge: 407 ha; Bama Kuno: 1092 ha; Finto Manareg: 1108 ha-see Figure 2 for location of forest parks in the West-

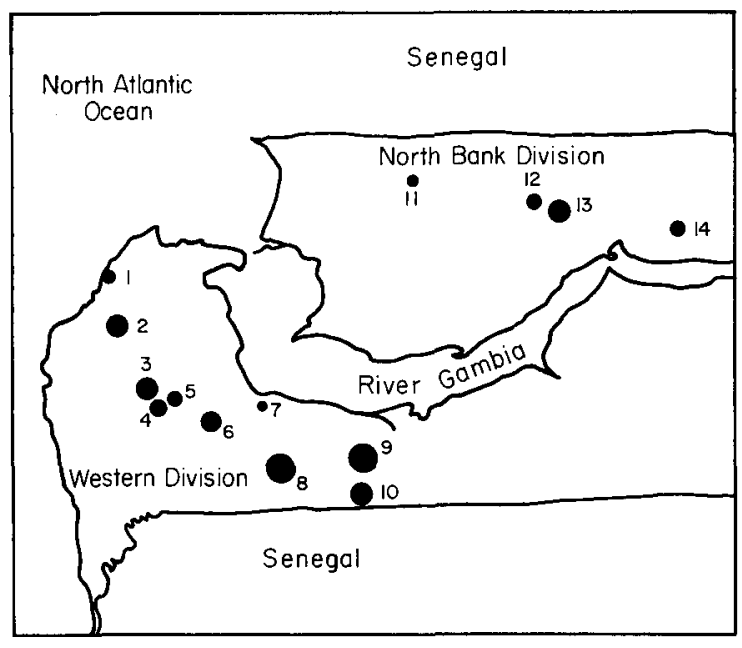

Figure 2. Map of the Western and North Bank Division showing the location of the forest parks.

Western Division Parks: (1) Bijilo; (2) Salagi;

(3) Bamba; (4) Nyambi; (5) Kabafita; (6) Furuyar;

(7) Pirang; (8) Finto Mareng; (9) Bama Kuno;

(10) Katilenge. North Bank Parks: (11) Lohen;

(12) Kasaywa; (13) Kumadi; (14) Marike. ern Division), have viable populations of red colobus, patas monkeys, green monkeys and baboons. Since there are detailed survey maps of all the forest parks and since the maintenance of the forest parks already has a well-established infrastructure in the Department of Forestry, it is probable that the best prospects for primate conservation rest in these forest parks. Forest parks could form the basis of a conservation system that would ensure the survival of representative habitats and much of the country's extant terrestrial fauna if they could be (a) properly policed and fenced so that they are kept free of human occupancy, fire, grazing and felling; (b) made economically viable through conventional forestry procedures and the introduction of limited educational tourism; and (c) be part of a programme that balances out the conservation interests on the one hand and the economic and social interests of the local people on the other.

On a general level there are three kinds of action that are urgently needed. Firstly, systematic surveys should be conducted in order to supply numbers and distribution patterns for all species. Currently, there is no reliable information on the past or present status, population trends, density, distribution or microhabitat preferences of any of the species. Secondly, conservation-oriented programmes should be incorporated into the core curricula of all primary and secondary schools in all classes so that they become an integral part of the educational development of all the children. Thirdly, as far as possible, solutions to wildlife problems should be sought through local opinions and choices, policy should be built within The Gambia at a grassroots level rather than imposed from above or from outside The Gambia.

More specifically, Parker (1973) suggested that (a) the forest parks should be considered as potential wildlife conservation units, as this would not involve the alienation of land from an already land-hungry people; (b) the forest parks in the Western Division should be used as tourist facilities and eventually become financially selfsupporting through tourist fees; and (c) the involvement with the zoo in the Abuko Nature Reserve be curtailed and that the time, energy and money saved spent on development of conservation. 
Along with Parker's suggestions it might also be worthwhile to investigate non-lethal ways for local farmers to protect their crops from marauding monkeys. These investigations would seem to be necessary since (a) one of the main drains on monkey populations is probably the killing of marauders and (b) according to the Wildlife Conservation Act of 1977 any person may take reasonably necessary measures to protect any crops or property from a direct and immediate attack by any wild animal. The communal monkey hunts discussed above are a result. This would be particularly important in the Upper River and MacCarthy Island Divisions, where the communal monkey hunts frequently take place, and in the Western Division along the forest park borders and in the areas between the forest parks so that the monkeys (particularly the patas monkeys and baboons, which have extremely large home ranges) can travel between parks. At present, it is unreasonable to expect the farmers, already under the pressure of inflation, increasing population pressure, unreliable rain patterns and often low soil fertility, to allow the monkeys to ruin their crops.

The illegal capture and smuggling of monkeys out of The Gambia and the habitat destruction that is occurring can be stopped only with proper policing and patrolling programmes. These will need an injection of funds, which will initially have to come from outside The Gambia. Considering the length and condition of the border, however, the control of smuggling may be extremely difficult.

Unfortunately, this brief report has been general rather than specific and relies frequently on anecdotes. It has attempted to outline only the most observable threats to the Gambian primates and discusses only the most obvious areas where solutions may lie. It is assumed that the collection of much-needed information in the form of reliable surveys will lead to a more specific report on the exact problems and their solutions.

\section{Acknowledgments}

I thank the Gambian Government for permission to study in The Gambia; the Wildlife Conservation Department for per- mission to study in the Abuko Nature Reserve; the Forestry Department and the Gambian-German Forestry Project for permission to visit various forest parks throughout the Western Division; The Exploration Fund and Sigma Chi for financial support; Mr Bangura, Mr Reeb and Mr Schindele for their time and assistance; D. Chivers, D. Currey, S. Harcourt, T. Lemmon, M. Mensink and J. Oates for their comments on an earlier draft of this paper; M. Basi, P. Dunko and $H$. Snuggity for their encouragement and patience.

\section{References}

Carter, N. and Currey, D. 1987. Illegal trade in wild baboons from The Gambia. In: The Trade in Live Wildlife Mortality and Transport Conditions (Ed. A. Thornton), Vol. 2, pp. 19-21. Environmental Investigation Agency, London.

Ellenberg, H., Galat-Luong, A, von Maydell, H-J., Muhlenberg, M., Panzer, K., Schmidt-Lorenz, R., Sumeer, M. and Szolnoki, T. 1988. Pirang Ecological Investigations In A Forest Island In The Gambia. Stiftung Walderhaltung in Afrika, Hamburg.

Forster, H. 1983. Evaluation of the National Forest Inventory of The Gambia, report no. 10. German Agency for Technical Cooperation, (GTZ), Feldkirchen, Germany.

Jones, T.S. 1950. Notes on the monkeys of Sierra Leone. Sierra Leone Agricultural Notes, 22, 1-10.

Mensink, M. 1986. Julia: a gorilla with an identity crisis. New Scientist, 1513, 68-69.

Mittermeier, R. 1987. Effects of hunting on rain forest primates. In: Primate Conservation in the Tropical Rain Forest (Eds C. Marsh and R. Mittermeier). Alan R. Liss, Inc., New York.

Monath, T.P., Craven, A., Adjukiewicz, A., Germain, M., Francy, D.B., Ferrara, L., Samba, E.M., N'Jie, H., Cham, K., Fitzgerald, S., Crippen, P.H., Simpson, D.I.H., Bowen, E.T.W., Fabiyi, A. and Salaun, J.-J. 1980. Yellow Fever in The Gambia, 1978-1979: epidemiologic aspects with observations on the occurrence of orungo virus infections. Am. J. Trop. Med. Hyg. 29 (5), 912-928.

Parker, I.S.C. 1973. Prospects for Wildlife Conservation in The Gambia. A Consultant Report to the Foreign and Commonwealth Office ODA's Project for a Land Resource of The Gambia. Unpublished Manuscript distributed to relevant departments in The Gambia.

Rains, B. and Johnson, M.S. 1976. Vegetation. In: The Agricultural Development of The Gambia: an Agricultural, Environmental and Socioeconomic Analysis (Eds $\mathrm{J}$ Dunsmore, B. Rains, G. Lowe, D. Moffatt, I. Anderson and J. Williams), pp. 159-164. Land Resource Study, Surbiton, Surrey, England.

Tappen, N. 1964. Primate Studies in Sierra Leone. Curr. Anthropol. 5, 339-340.

UNDP, 27th January 1987. Fourth Country Programme for The Gambia. Governing Council of the UNDP. New York.

E.D. Starin, Department of Anthropology, City University of New York, Graduate Center, 33 West 42nd Street, New York City, NY, USA. 